\title{
Effects of different principles of Traditional Chinese Medicine treatment on TLR7/NF-KB signaling pathway in influenza virus infected mice
}

Ying-Jie Fu ${ }^{1+}{ }^{1}$, Yu-Qi Yan ${ }^{1 \dagger}$, Hong-Qiong Qin ${ }^{1}$, Sha Wu${ }^{1}$, Shan-Shan Shi ${ }^{1}$, Xiao Zheng ${ }^{1}$, Peng-Cheng Wang ${ }^{1}$, Xiao-Yin Chen ${ }^{2^{*}}$, Xiao-Long Tang ${ }^{3^{*}}$ and Zhen-You Jiang ${ }^{1 *}$

\begin{abstract}
Background: Influenza virus is a single-stranded RNA virus that causes influenza in humans and animals. About 600 million people around the world suffer from influenza every year. Upon recognizing viral RNA molecules, TLR7 (Tolllike receptor) initiates corresponding immune responses. Traditional Chinese Medicines (TCMs), including Yinqiao powder, Xinjiaxiangruyin and Guizhi-and-Mahuang decoction, have been extensively applied in clinical treatment of influenza. Although the therapeutic efficacy of TCMs against influenza virus in vivo was reported previously, its underlying mechanisms are not clearly understood. This study aimed to investigate the immunological mechanisms in the treatment of influenza virus infected mice with three Chinese herbal compounds as well as the effect on TLR7/NF-kB signaling pathway during recovery.
\end{abstract}

Methods: Wild type and TLR7 KO C57BL/6 mice were infected with influenza virus FM1 and then treated with three TCMs. The physical parameters of mice (body weight and lung index) and the expression levels of components in TLR7/NF-KB signaling pathway were evaluated.

Results: After viral infection, Guizhi-and-Mahuang decoction and Yinqiao powder showed better anti-viral effect under normal condition. Compared to the viral control group, expression levels of TLR7, MyD88, IRAK4 and NF-KB were significantly reduced in all treatment groups. Furthermore, the three TCM treatment groups showed poor therapeutic efficacy and no difference in viral load compared to the viral control group in TLR7 KO mice.

Conclusion: Our study indicated that Guizhi-and-Mahuang decoction and Yinqiao powder might play a crucial role of anti-influenza virus by regulating TLR7/NF-KB signal pathway.

Keywords: Influenza virus, Traditional Chinese Medicine, TLR7/NF-kB signaling pathway, TLR7 gene knockout, Guizhiand-Mahuang decoction, Yinqiao powder, Xinjiaxiangruyin

\footnotetext{
*Correspondence: tchenxiaoyin@jnu.edu.cn; xltang@aust.edu.cn;

tjzhy@jnu.edu.cn

${ }^{+}$Ying-Jie Fu and Yu-Qi Yan are co-first authors

${ }^{1}$ Department of Microbiology and Immunology, School of Basic Medical

Sciences, Jinan University, Guangzhou 510632, Guangdong, China

${ }^{2}$ College of Traditional Chinese Medicine, Jinan University,

Guangzhou 510632, Guangdong, China

${ }^{3}$ Medical College, Anhui University of Science \& Technology,

Huainan 232001, Anhui, China
}

(c) The Author(s) 2018. This article is distributed under the terms of the Creative Commons Attribution 4.0 International License (http://creativecommons.org/licenses/by/4.0/), which permits unrestricted use, distribution, and reproduction in any medium, provided you give appropriate credit to the original author(s) and the source, provide a link to the Creative Commons license, and indicate if changes were made. The Creative Commons Public Domain Dedication waiver (http://creativecommons.org/ publicdomain/zero/1.0/) applies to the data made available in this article, unless otherwise stated. 


\section{Background}

Influenza virus causes seasonal epidemics and occasional pandemics in human beings and presents serious public health and economic problems [1]. Influenza viruses belong to the Orthomyxoviridae family, and are classified into three types, A, B, and C, in which type A virus (influenza A virus) is a major zoonotic pathogen [2]. Influenza A (H1N1) causes an acute respiratory infectious disease with symptoms including fever, cough, diarrhea or vomiting, muscle pain or fatigue, redness of eyes and even death [3]. The most effective means of protection against influenza is vaccination, but its effectiveness has been limited because etiological influenza A and B viruses constantly undergo antigenetic changes [4]. Several anti-influenza drugs have been developed, including M2 protein inhibitors and neuraminidase inhibitors (NAIs). However, nearly all influenza A (H3N2) viruses and part of influenza A (H1N1) viruses are adamantane resistant nowadays, which leaves NAIs the only option for the infection with these viruses [5]. Two NAIs, oseltamivir and zanamivir, are FDA approved for use against type A and type B influenza infections [6]. However, during the 2007-08 influenza season, emergence and transmission of oseltamivir-resistant type A (H1N1) viruses, with an $\mathrm{H} 274 \mathrm{Y}$ mutation in the neuraminidase, were observed in several countries in the Northern Hemisphere and then spread globally [7]. In recent years, researchers have also identified oseltamivir resistant influenza type A (H5N1) and type $B$ viruses [5], which makes it urgent for the research and development of new and effective antiinfluenza drugs.

Traditional Chinese Medicine (TCM) is an important means to prevent and control influenza in China. Yinqiao powder is a classic prescription from "Wen Bing Tiao Bian", a TCM compound created by Jutong Wu in Qin Dynasty. As a representative of cool acrid exteriorresolving method of TCM, Yinqiao powder is effective in preventing and treating viral infection diseases, which belong to the category of TCM warm diseases, for its antipyretic and anti-inflammatory effect. Yinqiao powder is commonly used for the prevention of influenza in clinic, and has been widely used in the treatment of influenza A [8]. As a recommended drug against wind-heat offender, heat-infected lung influenza, it was included in the latest Influenza Diagnosis and Treatment Program (2018 edition) by the Chinese National Health and Family Planning Commission. Researches have confirmed that Yinqiao powder contains chlorogenic acid [9], phillyrin $[10,11]$ and arctiin $[12,13]$, which showed pharmacological effects of anti-influenza virus.

Xinjiaxiangruyin is also a TCM compound from "Wen Bing Tiao Bian" to prevent dampness and heat, and is mainly used for the treatment of summer fever and heat stroke etc. Some scholars used Xinjiaxiangruyin to treat influenza virus infected mice in hot and humid environment, and found that it had remarkable anti-viral effect [14]. Although it consists of five herbs, Xinjiaxiangruyin has a precise combination, in which elsholtzia mainly contains flavonoids and coumarin compounds, which show heat-clearing dampness, anti-bacterial, antiinflammatory and other pharmacological effects [15]. In addition, magnolol, the main component of Cortex Magnoliae Officinalis, has antioxidative [16, 17], inflammation regulation [18], cancer cell inhibition [19] and other effects. At the same time, honokiol also has an anti-viral activity $[20,21]$.

Guizhi-and-Mahuang decoction is from classic Chinese medicine works "typhoid fever" written by $\mathrm{Mr}$. Zhang Zhongjing and has acrid-warm herbs for relieving superficies and sweating slightly. Modern pharmacological studies suggest that Guizhi-and-Mahuang decoction has the functions of anti-influenza virus [22], antipyretic analgesia [23], and anti-inflammatory and asthma [24]. Ephedrine has been used in clinic in the past hundreds of years since its discovery. The studies show that ephedrine plays a role in many organs and tissues, and its mechanism is complex, which involves various types of adrenergic receptors [25]. Cinnamon aldehyde contained in Ramulus Cinnamomi can inhibit the infection of influenza A/PR/8 virus [26] and viral myocarditis [27]. However, although these three Chinese herbal compounds can be used for anti-influenza therapy, the molecular signaling pathway involved remains to be clarified.

It is well established that Toll-like receptors (TLRs) are a major family of pattern recognition receptors [28] and play a crucial role in the recognition of microbial pathogens, thereby inducing innate immune responses in mammalian hosts [29]. Toll-like receptor 7 (TLR7) is expressed within intracellular vesicles [30] and recognizes the singlestranded RNA viruses, like vesicular stomatitis virus and influenza virus [31, 32]. It's highly expressed by plasmacytoid dendritic cells (DCs) and B cells [32], and involves in the pathways used by the innate immune cells in the recognition of viral pathogens [31]. The TLRs signaling can be divided into two signal transduction pathways [33]. First, myeloid differentiation primary response 88 (MyD88) associates with TLRs through TIR (Toll/IL1-receptor homologous region) to form a complex that recruits the downstream signal molecule interleukin-1 receptor-associated kinase 4 (IRAK4). Phosphorylation of IRAK4 activates interleukin-1 receptor-associated kinase 1 (IRAK1), which subsequently promotes the activation of TNF receptor associated factor 6 (TRAF6). Activated TRAF6 binds to ubiquitin conjugating enzyme (E2) to degrade IKK-gamma and activate TGF-beta activated kinase 1 (TAK1). Activated TAK1 catalyzes the phosphorylation of IKK- beta protein 
and forms a complex. The phosphorylation results in translocation of nuclear factor kappa-light-chain-enhancer of activated B cells (NF- $\mathrm{KB}$ ) related gene from cytoplasm into nucleus and activates the downstream mitogen-activated protein kinases (MAPK) pathway, thereby inducing the formation of activator protein-1 (AP-1), and production of inflammatory cytokines such as interleukin-6 (IL-6), interleukin-12 (IL-12) and Tumor Necrosis Factor- $\alpha$ (TNF- $\alpha$ ) [34]. Since NF-kB is activated by a large number of stimuli, tight molecular feedback loops normally prevent sustained cellular responses and excessive inflammation. During infection, some influenza viral particles are degraded by endosomal proteases, releasing the viral genome RNA and initiating TLR7 signaling $[35,36]$.

In this study, we first confirmed that influenza virus infection indeed activated the TLR7/NF- $\mathrm{KB}$ signaling pathway. We then infected the wild type and TLR7 KO mice with influenza virus, and applied three TCMs to evaluate their effects on lung injury recovery. Furthermore, expression levels of components in TLR7/NF-kB pathway were detected and the possible immunological mechanisms were explored.

\section{Methods}

\section{Information of experimental design and resources}

The information regarding the experimental design, statistics, and resources used in this study are attached in the minimum standards of reporting checklist (Additional file 1).

\section{Drug preparation and HPLC establishment}

Yinqiao powder (15 g Fructus Forsythiae, 15 g Flos Lonicerae, 9 g Radix Platycodonis, 9 g Herba Menthae, 6 g Herba Lophatheri, 5 g Radix Glycyrrhizae, 6 g Herba Schizonepetae, 6 g Fermented soybean, 6 g Fructus arctii, 10 g Rhizoma Phragmitis); Xinjiaxiangruyin (6 g Herba Moslae, $9 \mathrm{~g}$ Flos Lonicerae, $9 \mathrm{~g}$ Dolichos, $6 \mathrm{~g}$ Cortex Magnoliae Officinalis, 6 g Fructus Forsythiae). Guizhi-andMahuang decoction contained equal part of Mahuang Tang $(9$ g Herba Ephedrae, 6 g Ramulus Cinnamomi, 9 g Semen Armeniacae Amarum, 6 g Radix glycyrrhizae preparata) and Guizhi Tang (9 g Ramulus Cinnamomi, 9 g Radix Paeoniae Alba, 6 g Radix Glycyrrhizae, 9 g Rhizoma Zingiberis Recens, 3 g Jujube), which were dissolved in water and combined; These three drugs were all Chinese patented granules, which were purchased from China Resources Sanjiu Medical \& Pharmaceutical Co., Ltd. (Table 1). Oseltamivir Phosphate Capsules was obtained from Yichang Yangtze River East Sunshine pharmaceutical Ltd (Lot H20065415). 3,4-dihydroxybenzoic acid (Lot 170707); chlorogenic acid (Lot 171110); liquiritin (Lot 171222); forsythin (Lot 171103); arctiin (Lot 180207); thymol (Lot 171210); magnolol (Lot 171126); amygdalin (Lot 170902); paeoniflorin (Lot 180124) were purchased from Beijing Shengshi Kangpu Chemical Engineering Technology Institute, Ephedrine Hydrochloride (Lot: 171241-201508) was purchased from China Research Institute of Food and Drug Verification. $500 \mathrm{mg}$ of fine particles of each TCM was dissolved in $25 \mathrm{~mL}$ of $50 \%$ methanol solution, ultrasonic cleaning for $30 \mathrm{~min}$, and filtered with $0.45 \mu \mathrm{m}$ microporous filters. High performance liquid chromatography (HPLC) was performed to identify the main chemical constituents in the TCMs. Fingerprints of TCMs were read, and some chemical constituents of TCMs were identified according to the spectrograms and retention times of their standards (Fig. 1).

\section{Animals}

C57BL/6 wild type (WT) mice of SPF grade were purchased from Medical Animal Experiment Center of Guangdong Province (animal license \#: SCXK 20130002). TLR7 knockout (TLR7 KO) mice were provided by the Jackson Laboratory (USA) and all the knockout mice were returned to $\mathrm{C} 57 \mathrm{BL} / 6$ mice over ten generations. The breeding and feeding of TLR7 KO mice were carried out in SPF environment of Animal Experimental Center of Jinan University with free drinking water and feeding, in temperature-controlled animal facility (temperature: $20 \pm 2{ }^{\circ} \mathrm{C}$; humidity: $50 \%$ ) with $12 \mathrm{~h}$ diurnal cycle and individual ventilated cages (IVC). Sixty WT female C57BL/6 mice (6-8 weeks old) were randomly divided into six experimental groups $(n=10 /$ group $)$ : blank control group, virus control group, oseltamivir group (positive control group), Xinjiaxiangruyin group, Guizhiand-Mahuang decoction group, and Yinqiao powder group. The same protocol was applied to TLR7 KO mice. Mice were anesthetized by intraperitoneal injection of 130-160 $\mu \mathrm{L} 6 \%$ chloral hydrate solution, and $50 \mu \mathrm{L}$ sterile solution of $0.9 \% \mathrm{NaCl}$ was dropped nasally in blank control group. The rest groups were challenged with $50 \mu \mathrm{L}$ influenza virus FM1 suspension (dilution 1:640) nasally. None of the mice infected died. The drug dose was calculated based on body-weight differences between humans and mice and the dose for the mice was equivalent to 9.1 times that for human clinical dosage. $24 \mathrm{~h}$ after infection, $0.4 \mathrm{~mL}$ of Yinqiao powder $(560 \mathrm{mg} / \mathrm{mL})$, Xinjiaxiangruyin $(230 \mathrm{mg} / \mathrm{mL})$, Guizhi-and-Mahuang decoction $(350 \mathrm{mg} /$ $\mathrm{mL})$ and oseltamivir $(1.5 \mathrm{mg} / \mathrm{mL})$ were given to mice in treatment groups by gastric gavage once a day for 5 days, respectively. The blank control group and virus control group were treated with the same amount of double distilled water. The mice were placed in an artificial climate incubator (temperature: $18-20{ }^{\circ} \mathrm{C}$; humidity: $50 \%$; light: $3000 \mathrm{Lx}$ ) and a free diet during the experiment and were observed for 5 days. The mice were sacrificed to collect lung and spleen for examination 6 days after infection. 
Table 1 The compositions of Traditional Chinese Medicine

\begin{tabular}{|c|c|c|c|c|c|c|}
\hline $\begin{array}{l}\text { Traditional Chinese } \\
\text { Medicine }\end{array}$ & No. & Herbal drug & Official name & Local name & Batch number & Collection place \\
\hline \multirow[t]{10}{*}{ Yinqiao powder } & 1 & Fructus Forsythiae & $\begin{array}{l}\text { Forsythia suspensa (Thunb.) } \\
\text { Vahl }\end{array}$ & Lianqiao & $1712002 S$ & Shanxi \\
\hline & 2 & Flos Lonicerae & Lonicera japonica Thunb. & Jinyinhua & $1801002 S$ & Shandong \\
\hline & 3 & Radix Platycodonis & $\begin{array}{l}\text { Platycodon grandiflorus (Jacq.) } \\
\text { A.DC. }\end{array}$ & Jugeng & $1712004 S$ & Anhui \\
\hline & 4 & Herba Menthae & Mentha haplocalyx Briq. & Bohe & $1709001 S$ & Jiangsu \\
\hline & 5 & Herba Lophatheri & Lophatherum gracile Brongn. & Danzhuye & $1712002 S$ & Sichuan \\
\hline & 6 & Radix Glycyrrhizae & Glycyrrhiza uralensis Fisch. & Gancao & $1801016 S$ & Gansu \\
\hline & 7 & Herba Schizonepetae & Schizonepeta tenuifolia Briq & Jingjiesui & $1710001 S$ & Hebei \\
\hline & 8 & Fermented soybean & Glycine max (L.) Merr. & Dandouchi & $1704001 S$ & Henan \\
\hline & 9 & Fructus arctii & Arctium lappa L. & Niubangzi & $1801001 S$ & Gansu \\
\hline & 10 & Rhizoma Phragmitis & Phragmites communis Trin. & Lugen & $1709002 S$ & Anhui \\
\hline \multirow[t]{5}{*}{ Xinjiaxiangruyin } & 1 & Herba Moslae & Mosla chinensis Maxim. & Xiangru & $1708002 S$ & Jiangxi \\
\hline & 2 & Flos Lonicerae & Lonicera japonica Thunb. & Jinyinhua & 18010025 & Shandong \\
\hline & 3 & Dolichos & Dolichos aciphyllus R.Wilczek & Biandouhua & 161001 & Guangdong \\
\hline & 4 & Cortex Magnoliae Officinalis & $\begin{array}{l}\text { Magnolia officinalis Rehder \& } \\
\text { E.H.Wilson }\end{array}$ & Houpu & $1712003 S$ & Sichuan \\
\hline & 5 & Fructus Forsythiae & $\begin{array}{l}\text { Forsythia suspensa (Thunb.) } \\
\text { Vahl }\end{array}$ & Lianqiao & $1712002 S$ & Shanxi \\
\hline \multirow[t]{8}{*}{$\begin{array}{l}\text { Guizhi-and-Mahuang decoc- } \\
\text { tion }\end{array}$} & 1 & Herba Ephedrae & $\begin{array}{l}\text { Ephedra intermedia Schrenk } \\
\text { \& C.A.Mey. }\end{array}$ & Mahuang & $1706004 S$ & Neimenggu \\
\hline & 2 & Ramulus Cinnamomi & $\begin{array}{l}\text { Cinnamomum cassia (L.) } \\
\text { J.Presl }\end{array}$ & Guizhi & $1801003 S$ & Guangxini \\
\hline & 3 & Semen Armeniacae Amarum & Prunus armeniaca $\mathrm{L}$. & Xingren & $1712003 S$ & Hebei \\
\hline & 4 & Radix glycyrrhizae preparata & Glycyrrhiza uralensis Fisch. & Zhigancao & $1712003 S$ & Gansu \\
\hline & 5 & Radix Paeoniae Alba & Paeonia lactiflora Pall. & Shaoyao & 18010015 & Anhui \\
\hline & 6 & Radix Glycyrrhizae & Glycyrrhiza uralensis Fisch. & Gancao & $1801016 S$ & Gansu \\
\hline & 7 & Rhizoma Zingiberis Recens & Zingiber officinale Roscoe & Shengjiang & - & Guangdong \\
\hline & 8 & Jujube & Ziziphus jujuba Mill. & Dazao & - & Guangdong \\
\hline
\end{tabular}

\section{Virus strains}

Virus strain: type A influenza virus, FM1 mouse lung adapted strain (FM1), stored at $-80{ }^{\circ} \mathrm{C}$. It was provided by the Department of Microbiology and Immunology, School of Basic Medical Sciences, Jinan University. The hemagglutination titer was 1:40 after two times of routine chick embryo resuscitation. The mortality of mice 14 days after virus infection at different concentrations was determined by double dilution method. The virus concentration causing 20\% mouse mortality (blood coagulation titer $1: 640$ ) was used and $50 \mu \mathrm{L}$ of virus solution was given to each mouse.

\section{The changes of body weight, animal condition, survival rate and lung index}

Starting at 2 days before infection, the weight of each mouse was recorded at the same time point every day. The changes of symptoms, water and food intake, hair color, activity, survival time, death condition and so on were observed twice a day. The mice were sacrificed
6 days after infection for lung tissue collection. Adipose tissue was removed, and the lung tissue was washed with sterile phosphate buffer saline (PBS). The lungs were then dried with filter paper and weighed. The lung index was calculated using the formula: lung index=lung weight/ body weight $\times 100 \%$.

\section{Observation of pathological changes in lung tissue}

The fresh lungs were fixed in $4 \%$ paraformaldehyde, dehydrated, embedded in paraffin wax and serially sectioned at $5 \mu \mathrm{m}$. Haematoxylin and eosin $(\mathrm{H} \& \mathrm{E})$ was employed and the pathological changes of the lung tissue were observed under light microscope.

\section{Detection of the level of Th17 and Treg cells in the spleen of mice}

The spleens of mice were rinced with RPMI-1640 medium and continuously grounded. The resultant cell suspension was placed on the upper layer of the lymphocyte separating fluid (Multi Sciences, China). After 
a

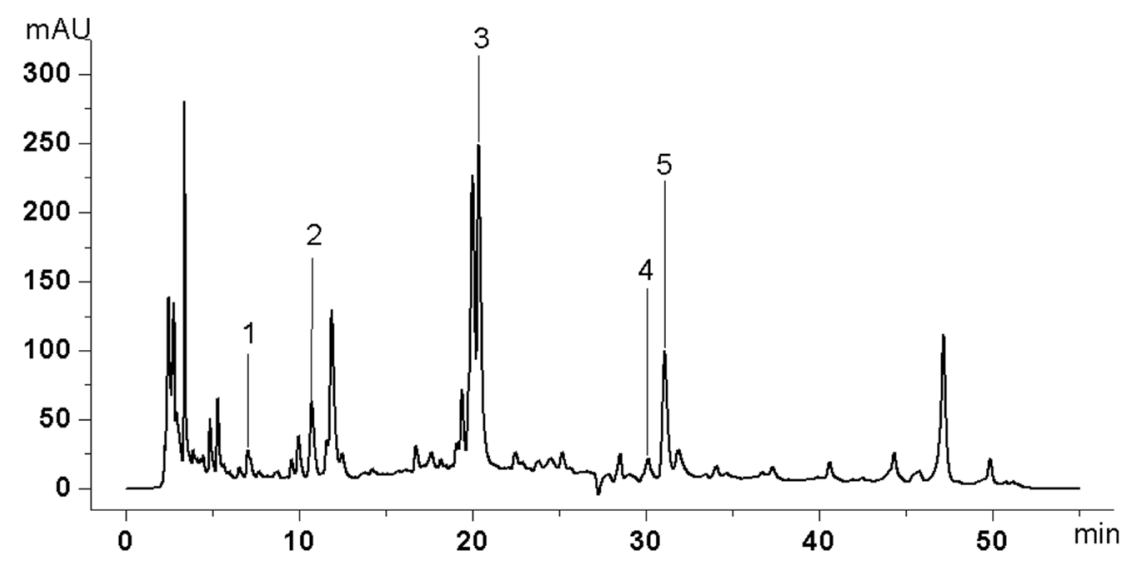

b

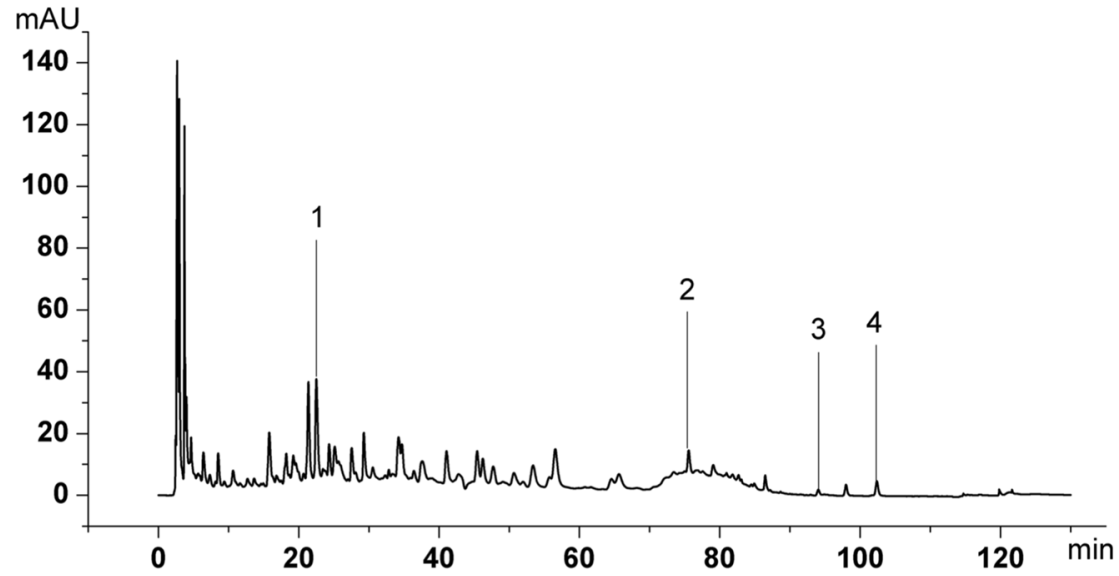

C

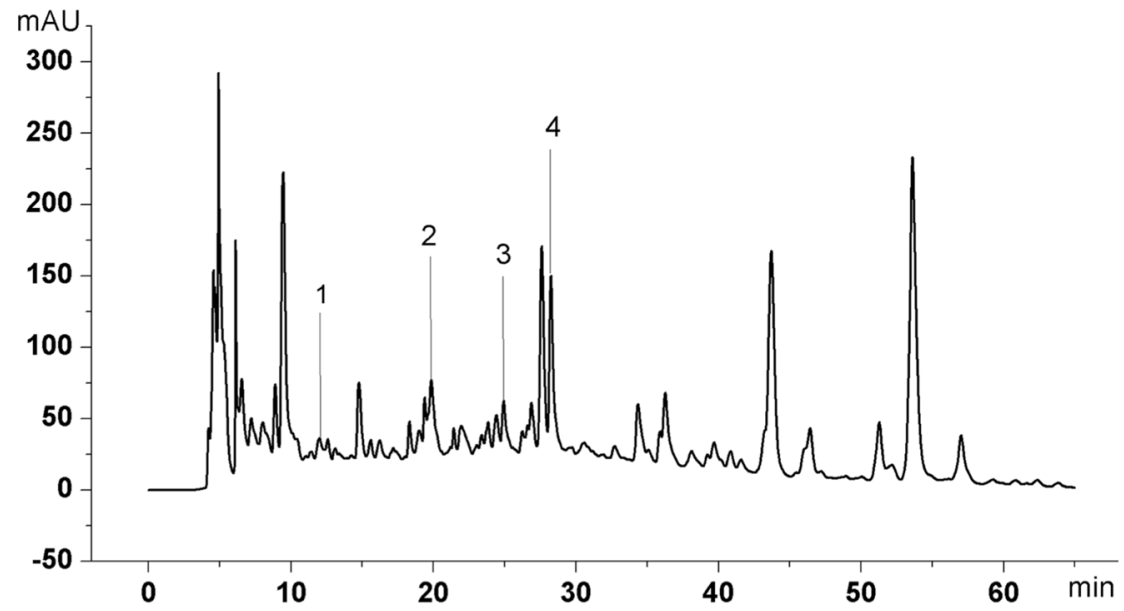

Fig. 1 The fingerprints of TCMs. a The fingerprint of Yinqiao powder; peak number and identity, 1:3,4-dihydroxybenzoic acid; 2: chlorogenic acid; 3: liquiritin; 4: forsythin; 5: arctiin. b The fingerprint of Xinjiaxiangruyin; peak number and identity, 1: chlorogenic acid; 2: forsythin; 3: thymol; 4: magnolol. c The fingerprint of Guizhi-and-Mahuang decoction; peak number and identity, 1: ephedrine hydrochloride; 2: amygdalin; 3: paeoniflorin; 4: liquiritin 
centrifugation, the intermediate white lymphocyte layer was collected and washed with PBS. Lymphocytes were then resuspended in RPMI-1640 medium containing $10 \%$ fetal bovine serum (FBS) and adjusted to $1 \times 10^{6} / \mathrm{mL}$ concentration. To detect Treg cells, $100 \mu \mathrm{L}$ of cell suspension was incubated with anti-CD4 and anti-CD25 antibodies for $30 \mathrm{~min}$ at $4{ }^{\circ} \mathrm{C}$ avoiding light, and then washed with precooled PBS. Cells were then resuspended in film breaking working fluid (fixation/ permeabilization concentrate: fixation/permeabilization diluent $=1: 3)(\mathrm{eBioscience}, \mathrm{USA})$, and incubated for $30 \mathrm{~min}$ at $4{ }^{\circ} \mathrm{C}$ avoiding light. After washed with $1 \times$ Permeabilization buffer (eBioscience, USA), intracellular antibody Foxp3 was added and incubated for $30 \mathrm{~min}$ at $4{ }^{\circ} \mathrm{C}$ avoiding light. Finally, cells were washed and resuspended in $200 \mu \mathrm{L}$ of PBS for analysis on FACSVerse Flow cytometry (Becton-Dickinson Bioscie NCS, Franklin Lakes, NJ, USA). Flowjo7.6.1 (Flow Jo, Ashland, OR, USA) software was used to process and analyze the experimental data. The Antibodies were shown in Table 2.

\section{Detection of mRNA expression levels of TLR7, MyD88, IRAK4 and NF-KB in mouse lung with RT-qPCR}

The lung tissue was collected for total RNA extraction using Trizol (TaKaRa, Japan) according to the manufacturer's instructions. First-strand cDNA synthesis and the $\mathrm{SYBR}^{\circledR}$ Green $\mathrm{qPCR}$ assay were performed using the PrimeScript ${ }^{\mathrm{TM}}$ RT Reagent Kit (TakaRa, Japan). The reverse transcription reactions were performed in the Bio-Rad S1000 ${ }^{\mathrm{TM}}$ thermocycler (Bio-Rad, USA), qPCR protocol was: $95{ }^{\circ} \mathrm{C}, 30 \mathrm{~s} ; 95{ }^{\circ} \mathrm{C}, 5 \mathrm{~s} ; 60{ }^{\circ} \mathrm{C}, 30 \mathrm{~s}$; with 40 amplification cycle; $95{ }^{\circ} \mathrm{C}, 10 \mathrm{~s}$ using the ABI 7000 Real Time PCR machines. All primers (Table 3) were designed and synthesized by Shanghai Generay Biotech Co. Ltd. Corresponding relative mRNA expression was calculated by the $2^{-\Delta \Delta \mathrm{Ct}}$ method [37]. mRNA expression levels of FM1, TLR7, MyD88, IRAK4 and NF-kB were evaluated using GAPDH as an internal standard control.

Table 2 Antibodies used for flow cytometry

\begin{tabular}{llll}
\hline Antibody & Clone & Company & Labels used \\
\hline CD4 & RM4-5 & eBioscience & PE \\
IL-17A & eBio17B7 & eBioscience & FTIC \\
CD25 & PC61.5 & eBioscience & APC \\
Foxp3 & FJK-16s & eBioscience & PE-cy5.5 \\
\hline
\end{tabular}

PE phyco-erythrin, FITC Fluorescein isothiocyanate, APC allophycocyanin, CD4 cluster of differentiation 4, IL-17A interleukin-17A, CD25 cluster of differentiation 25, Foxp3 forkhead box P3
Table 3 Primers used for RT-qPCR studies

\begin{tabular}{|c|c|c|}
\hline Gene & Forward ( $5^{\prime}$ to $\left.3^{\prime}\right)$ & Reverse ( $5^{\prime}$ to $\left.3^{\prime}\right)$ \\
\hline FM1 & GACCAATCCTGTCACCTCTGAC & $\begin{array}{l}\text { AGGGCATTNTGGACAAAG } \\
\text { CGTCTA }\end{array}$ \\
\hline GAPDH & $\begin{array}{l}\text { CTGAGCAAGAGAGGCCCT } \\
\text { ATCC }\end{array}$ & CTCCCTAGGCCCCTCCTGTT \\
\hline TLR7 & GGGTCCAAAGCCAATGTG & TGTTAGATTCTCCTTCGTGATG \\
\hline MyD88 & $\begin{array}{l}\text { CGATTATCTACAGAGCAAGGA } \\
\text { ATG }\end{array}$ & ATAGTGATGAACCGCAGGATAC \\
\hline IRAK4 & CATCGTGGCGGTGAAGAAG & AGCATACACTAAGCACAGGTTG \\
\hline$N F-k B$ & ATTCTGACCTTGCCTATCTAC & TCCAGTCTCCGAGTGAAG \\
\hline
\end{tabular}

GAPDH glyceraldehyde-3-phosphate dehydrogenase, TLR7Toll-like receptor 7, MyD88 Myeloid differentiation primary response 88, IRAK4 interleukin-1 receptor-associated kinase 4, NF-KB nuclear factor kappa-light-chain-enhancer of activated $B$ cells

\section{Determination of protein expression levels of TLR7, MyD88, IRAK4 and NF-KB by Western-blotting}

Protein samples were extracted from lung tissue homogenate using a RIPA lysis buffer (Multi Sciences, China) supplemented with protease and phosphatase inhibitors, and the protein concentrations were quantified using BCA assay. Separated with $10 \%$ SDS-PAGE, the protein was transferred wetly to the PVDF membrane (Millipore, USA). The PVDF membrane was blocked in TBST containing 5\% skimmed milk and incubated with the Rabbit monoclonal antibody (mAb) (CST, USA) of GAPDH, TLR7, MyD88, IRAK4 and NF-kB overnight at $4{ }^{\circ} \mathrm{C}$, respectively, and then incubated for $2 \mathrm{~h}$ in the HRP-labeled secondary antibodies against rabbit (Multi Sciences, China). The blots were developed using the ECL color display kit (Multi Sciences, China), and ImageJ image analysis software was used for ALIANCE gel image analyzer and imaging.

\section{Statistical analysis}

The experiment data were processed and analyzed with the statistical software SPSS 13.0. All results were presented as mean \pm standard deviation $(x \pm s)$. Two groups of independent samples were compared by t-test. Multiple experimental groups were analyzed by ANOVA in advance, and SNK was used for comparison of each two groups according to the homogeneity of variance test. $\mathrm{P}<0.05$ indicated that the difference was statistically significant, and $\mathrm{P}<0.01$ means significant difference.

\section{Results \\ Guizhi-and-Mahuang decoction had a protective effect on virus infection}

To evaluate the effects of TCMs on anti-virus and development of lung inflammation, we infected wild-type and 
TLR7 KO C57BL/6 mice with Influenza virus FM1 and applied Oseltamivir and three TCMs $24 \mathrm{~h}$ post-infection for 5 days, respectively. In wild-type mice, the animals in sham group had good mental state, good hair color, quick action, breathing, normal gait and natural weight growth. Clinical symptoms in virus infected mice were apparent 2 days after infection. In viral control group, mice had typical flu symptoms, including hair discoloring, towering hair, curled up, arch, paralysis, loss of appetite, reduced water drinking, convulsions, faint and breathing difficulties. Meanwhile the body weight was decreased gradually. Compared to virus control, animals in Oseltamivir group, Guizhi-and-Mahuang decoction group were significantly improved with towering hair, convulsions and other symptoms remarkably reduced. Yinqiao powder group only showed slightly improvement. The body weight changes in each group were shown in Fig. 2a. The average body weight of mice on day 6 in virus control group, Xinjiaxiangruyin group and Yinqiao powder group were decreased to $72.08 \%, 75.16 \%$ (NS) and $79.94 \%$ $(\mathrm{P}<0.05)$ of the original body weight, respectively, while mice in Oseltamivir group and Guizhi-and-Mahuang decoction group were better with $93.29 \%(\mathrm{P}<0.01)$ and $84.45 \%(\mathrm{P}<0.01)$ of the original body weight, respectively.
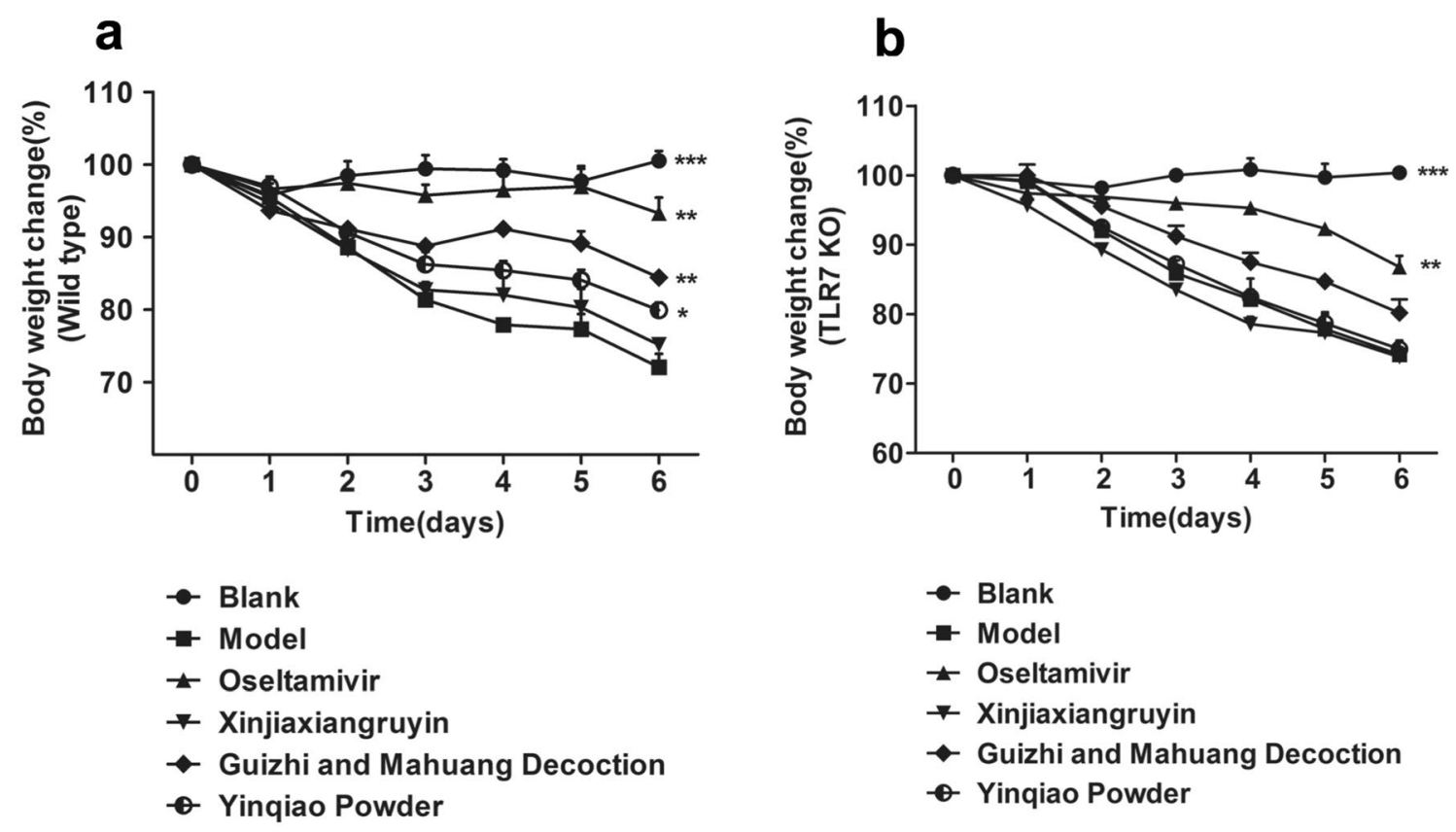

C

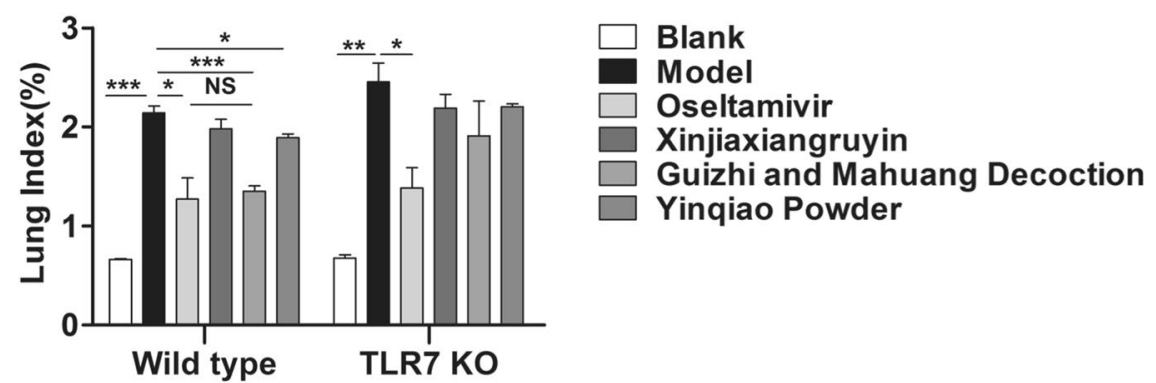

Fig. 2 Effects of three TCM compounds on body weight loss and lung index of mice infected with influenza virus. C57BL/6 wild type (a) and TLR7 KO (b) mice were infected with $50 \mu \mathrm{L} F \mathrm{FM}$ virus and then were gavaged with distilled water, containing Oseltamivir, Xinjiaxiangruyin, Guizhi-and-Mahuang decoction or Yinqiao powder daily $24 \mathrm{~h}$ after virus infection, respectively. Changes in body weight of each mouse were recorded. Each group was compared to the model group. c The body weight of infected mice and blank were monitored every day for 6 days. The mice were sacrifice on day 6 , and the total lung were completely removed and weighed. Lung index $=$ lung weight/body weight $\times 100 \%$. ${ }^{*} P<0.05$, ${ }^{*} \mathrm{P}<0.01,{ }^{* *} \mathrm{P}<0.001$ 
In TLR7 KO mice, we observed that, except for the blank group and the Oseltamivir group, the body weight of the virus control group and the three TCM groups decreased significantly (Fig. 2b). We further weighed the whole lung of each mouse and calculated the lung index. As shown in Fig. 2c, in both wild type and TLR7 KO mice, there was a significant difference in the lung index between the blank group and the virus control group $(\mathrm{P}<0.01)$, indicating that the viral infection was successful. As a positive control drug, Oseltamivir significantly reduced lung index compared to the virus control group $(\mathrm{P}<0.05)$. In wild type mice, the lung indexes of animals in Guizhiand-Mahuang decoction group and Yinqiao powder were significantly decreased compared to the virus control group $(\mathrm{P}<0.05)$; and there was no significant difference (NS) between Guizhi-and-Mahuang decoction group and Oseltamivir group. In TLR7 KO mice, the three TCM groups had no significant difference compared to the virus control group or among three groups (NS).

\section{Pathological changes of lung tissue}

The amount of replicating virus in the lungs is thought to correlate with the degree of lung pathological changes. Therefore, wild type and TLR7 KO mice were infected with Influenza FM1 virus, and four drugs were used to treat the mice $24 \mathrm{~h}$ after infection, respectively. After 5 days of continuous gavage, lungs of the mice were collected. The RNA was extracted from the left lung, and the replication of virus in each group was evaluated. We observed that the virus control group had a significantly higher viral mRNA expression level in lung tissue than blank group in wild type mice $(\mathrm{P}<0.001)$, Meanwhile, Oseltamivir, Guizhi-and-Mahuang decoction and Yinqiao powder dramatically decreased the viral load compared to the virus control group $(\mathrm{P}<0.001)$. In TLR7 KO mice, the viral load of virus control group was significantly higher than that of blank control group $(\mathrm{P}<0.001)$, but only Oseltamivir group reduced the replication of virus $(\mathrm{P}<0.05)$. We then performed comparative analysis between wild type and TLR7 KO mice, and found no difference between virus control groups. However, Oseltamivir, Guizhi-and-Mahuang decoction and Yinqiao powder treatment induced significant difference between wild type and TLR7 KO mice, suggesting that TLR7 receptor played a key role in antivirus effects (Fig. 3).

At the same time, the right lungs of mice were fixed in $4 \%$ formaldehyde solution and HE staining was performed. In wild type mice (Fig. 4a), blank control group showed clear and intact alveolar structure. The alveolar wall was thin, and there was no inflammatory secretion in alveolar cavity, nor alveolar interstitial infiltration of inflammatory cells. In virus control group, inflammatory

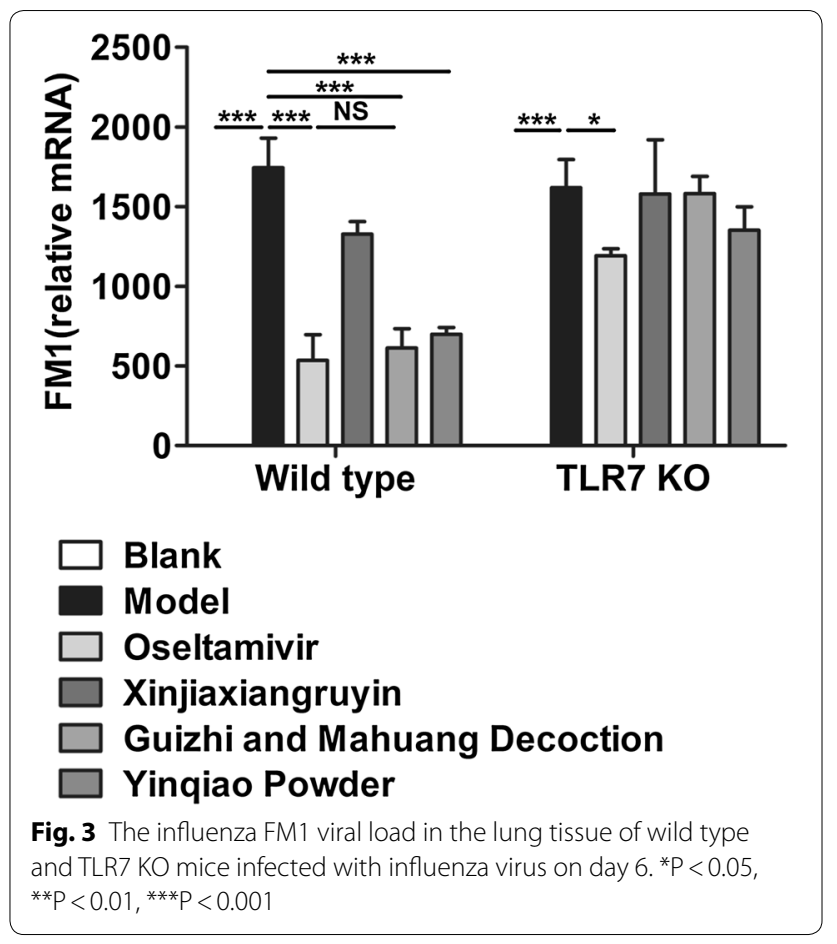

damage was observed in lung tissue, including a large number of inflammatory cell infiltration in alveolar cavity, alveolar septum thickening and severe interstitial edema, vascular congestion, bronchial obstruction due to inflammatory exudation. Formation of cavitation was also observed after epithelial cell shedding or necrosis. In the positive control group (oseltamivir group), alveolar inflammatory cells were significantly reduced and peribronchial alveolar wall was thinning with no inflammatory cells, similar to that in the blank control group, and only alveolar wall thickening was observed. In Xinjiaxiangruyin group, alveolar structure destruction was increased. Bronchial wall and alveolar septa were thickened, and there were a large number of infiltrating mononuclear cells, with bronchiole having more infiltrating inflammatory cells. In Guizhi-and-Mahuang decoction group, the inflammatory lesion was more significantly reduced than that in virus control group. The alveolar wall was thin, with less infiltration of mononuclear cells, capillary dilatation and congestion of alveolar wall. The alveolar septum was not obviously thickened, with only a small number of mononuclear cells and lymphocytes. There was no inflammatory exudation in bronchiole, similar to that in the positive control group. In Yinqiao powder group, the alveolar wall was thickened, but alveolar infiltration was not obvious. Compared to the virus control group, the alveolar infiltration and inflammatory reaction was milder and there was no exudate in the bronchiole. In general, the influenza viral 


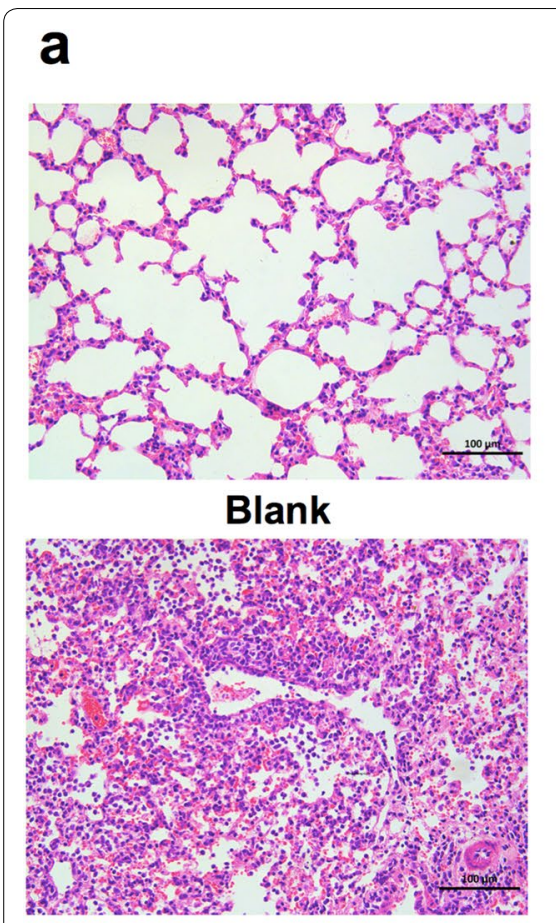

Xinjiaxiangruyin

b

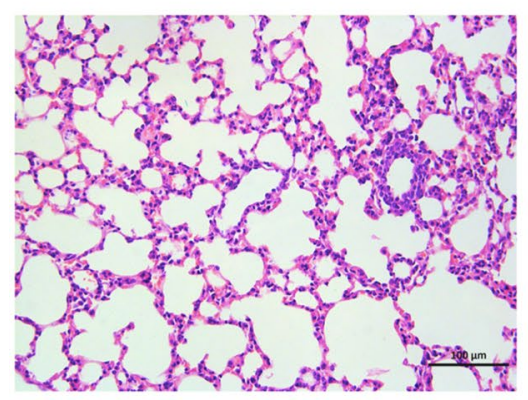

Blank

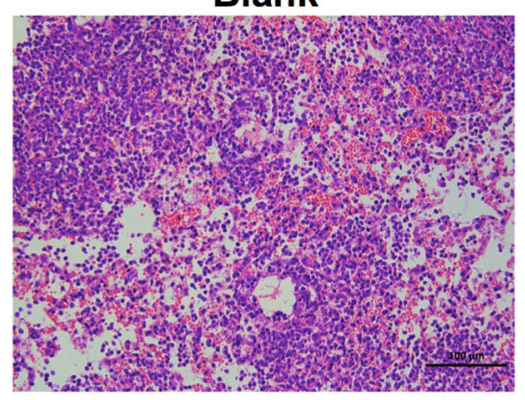

Xinjiaxiangruyin

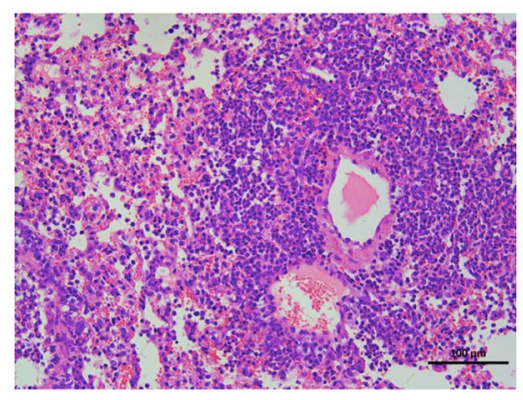

Model

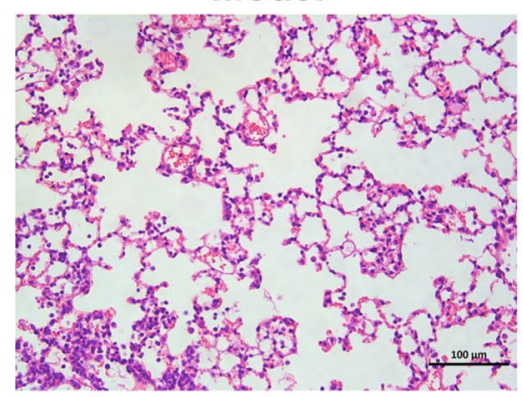

Guizhi and Mahuang Decoction

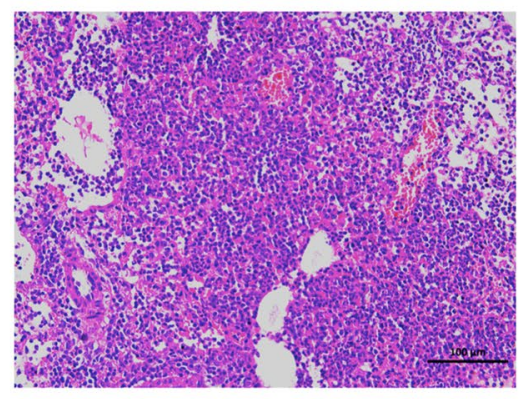

Model

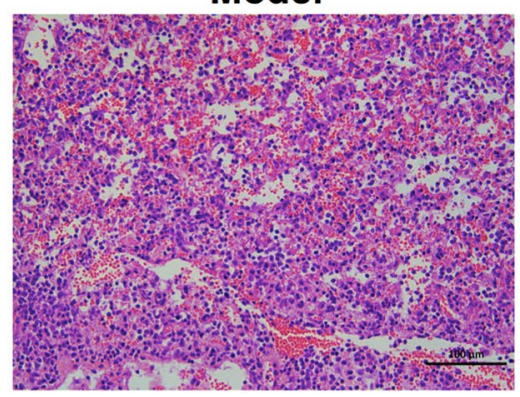

Guizhi and Mahuang Decoction

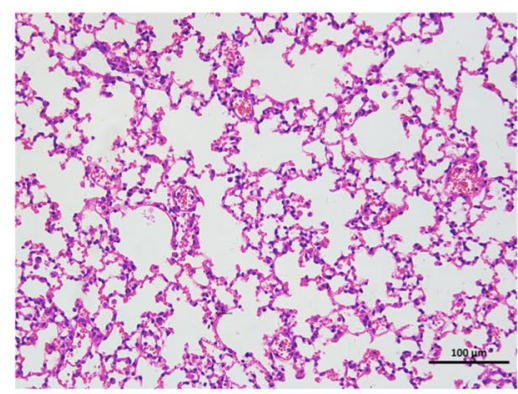

Oseltamivir

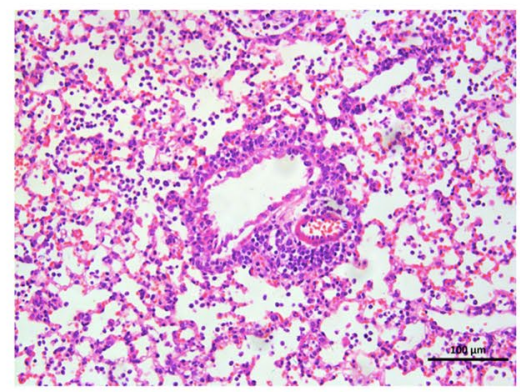

Yinqiao Powder
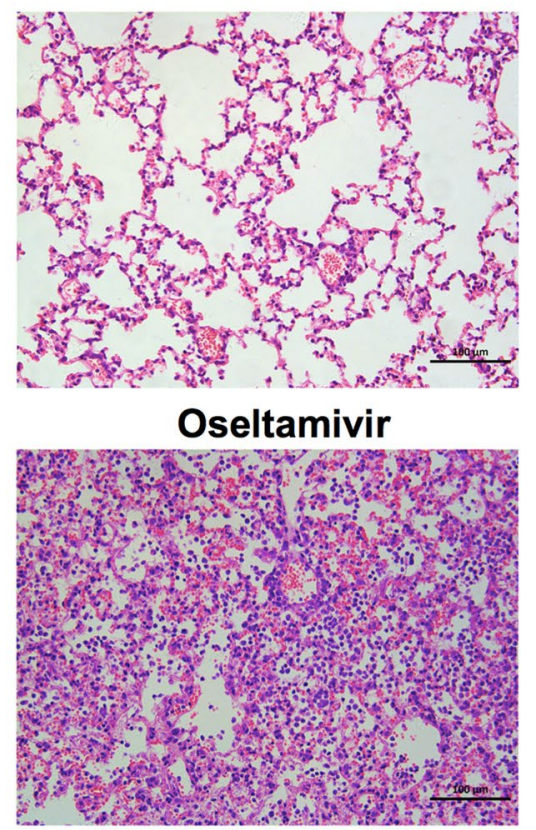

Yinqiao Powder

Fig. 4 Lung histopathology in wild type and TLR7 KO mice infected with influenza FM1. The lungs were collected on day 6 postinfection, and sections were prepared for histopathological analysis. $\mathbf{a}, \mathbf{b}$ Indicate C57BL/6 wild mice and TLR7 KO mice, respectively. This figure shows representative results of experiments with ten mice in each group. Bars $=100 \mu \mathrm{m}$ 
infection caused acute inflammatory responses and mononuclear cell infiltration in the respiratory tissue, which contributed to the main pathological basis of the disease. In TLR7 KO mice (Fig. 4b), the Oseltamivir treatment remarkably reduced inflammation compared to virus control. However, neither TCM treatment groups showed any difference compared to the virus control, which indicated that the therapeutic effects of TCM on viral infection induced inflammation needed the participation of TLR7 signaling.

\section{Profiling of Th17 cells and Treg cells in splenocytes}

In the process of immuno-regulation, Th17 cells are closely related to Treg cells. IL-17 secreted by Th17 cells can aggravate the inflammatory responses, while Treg cells can reduce the production of inflammatory cytokines and antibody secretion to inhibit immune responses. Th17/Treg balance plays an important role in maintaining the immune homeostasis of the body. In order to further verify the inflammatory response in mice, we used flow cytometry to detect the splenocytes in mice. As shown Fig. 5, in the wild type mice, the ratio of Th17 cells and Treg cells in the virus control group was significantly higher than that in the blank control group $(\mathrm{P}<0.001)$. Compared to the virus control, except for Xinjiaxiangruyin group, ratios of Th17 cells and Treg cells in other three groups were significantly decreased (Fig. 5a). In TLR7 KO mice, the ratio of Th17 cells and Treg cells in the virus control group was higher than that in the blank control group. Compared to the virus control group, only the Oseltamivir treatment resulted in significant decrease in the Th17 cell and Treg cell ratio $(\mathrm{P}<0.05)$ (Fig. 5b).

\section{Effects of drugs on TLR7/NF-KB signaling pathway}

In order to further explore the contribution of Chinese herbal compounds to innate immune response after influenza virus infection, wild type and TLR7 KO mice were infected with influenza virus, respectively. 6 days after infection, the mRNA relative expression and protein levels of components in TLR7 and NF- $\mathrm{KB}$ signaling pathways in lung tissue were detected with RT-qPCR and western blotting, respectively. As shown in Fig. 6, virus infection induced significant increase in the mRNA levels of TLR7, MyD88, IRAK4 and NF- $k B$ in wild type mice compared to blank control $(\mathrm{P}<0.001)$. Compared to the virus control group, all treatment, except for Xinjiaxiangzhuyin, resulted in significant decrease in expression levels of TLR7, MyD88, IRAK4 and NF-кB $(\mathrm{P}<0.05)$, with Oseltamivir and Guizhi-and-Mahuang decoction treatment having more reduction, followed by Yinqiao powder. These data indicated that influenza virus infection could activate TLR7/NF-kB signaling pathway, while Oseltamivir and Guizhi-and-Mahuang decoction significantly suppressed their expression. We also tested the TLR7 KO mice at the same time. The relative mRNA expression of TLR7 was significantly lower than that in wild type mice, and had no difference among all experimental groups (NS), which confirmed the success of TLR7 KO. Then, we studied the effect of TLR7 gene silencing on the downstream signaling pathway, and found that MyD88 and NF-kB were still activated. We further demonstrated that virus infection increased protein expression levels of TLR7, MyD88, IRAK4 and NF-kB with western blotting, while Oseltamivir, Guizhiand-Mahuang decoction, Yinqiao powder decreased their expression. The protein levels in each group were in accordance with the expression of mRNA (Fig. 7).

\section{Discussion}

Viruses activate immune pathways through three pattern recognition receptors (PRRs), TLRs, RLHs and NLRs (nucleotide-oligomerization domin (NOD) -like receptors) [38-40]. TLR7 recognizes the single-stranded RNA viruses, such as vesicular stomatitis virus and influenza virus [29]. Some studies have shown that TLR7 is mainly expressed in lung, placenta, heart, spleen, bone marrow, lymph nodes and other tissues [34, 41], so we detected mRNA and protein expression levels of TLR7 and its related genes in lung tissue in a mouse model. We infected wild type and TLR7 KO C57BL/6 mice with influenza virus in a normal environment, and applied various TCM treatment to evaluate their anti-virus and anti-inflammation effects. The viral load of the lung tissue in the virus control group was significantly higher than that in the blank control group, indicating that the experimental animal model was successfully established.

The drugs used in our study was selected according to the three main dialectic methods of TCM at the onset of diseases: acrid-warm herbs relieving superficies (Yinqiao powder), cold-pungent diaphoresis (Guizhi-and-Mahuang decoction), and clearing damp

\footnotetext{
(See figure on next page.)

Fig. 5 Profiling of Th17 cells and Treg cells in splenocytes of mice. C57/6 wild type mice ( $n=10 /$ group) and TLR7 KO mice ( $n=10 /$ group) were infected with $50 \mu \mathrm{L}$ of influenza FM1 virus. Splenocytes were isolated from 3 mice out of each group on day 6 post-infection and Th17 cell and Treg cell response were assayed in wild type mice $(\mathbf{a})$ and TLR7 KO mice $(\mathbf{b})$. Data are presented as the mean \pm SEM. Th17 cell response was determined by intracellular CD4, IL-17 staining. Treg cell response was determined by intracellular CD4, CD25 and Foxp3 staining. Data are presented as representative density plots in wild type mice $(\mathbf{c})$ and TLR7 KO mice $(\mathbf{d}) .{ }^{*} \mathrm{P}<0.05$, ${ }^{* *} \mathrm{P}<0.01,{ }^{* * *} \mathrm{P}<0.001$
} 
a

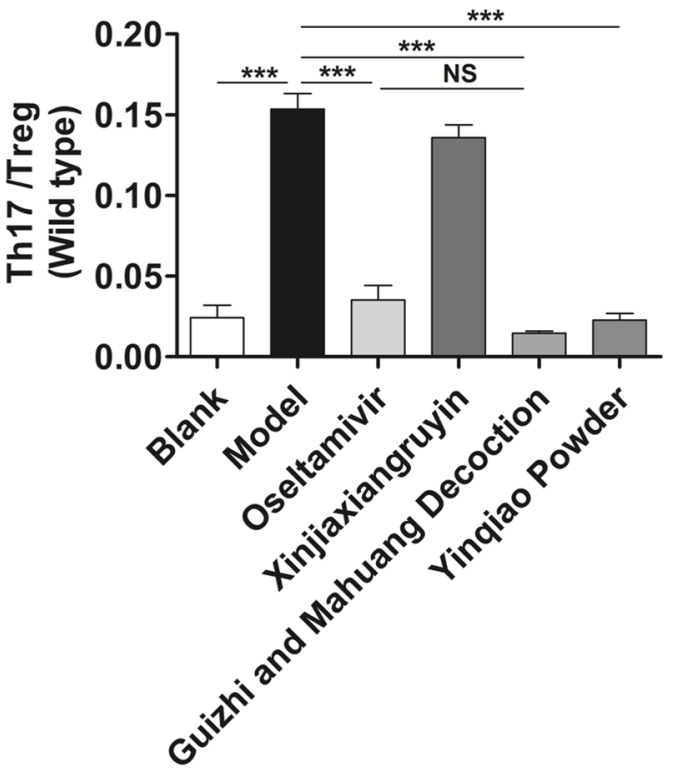

b

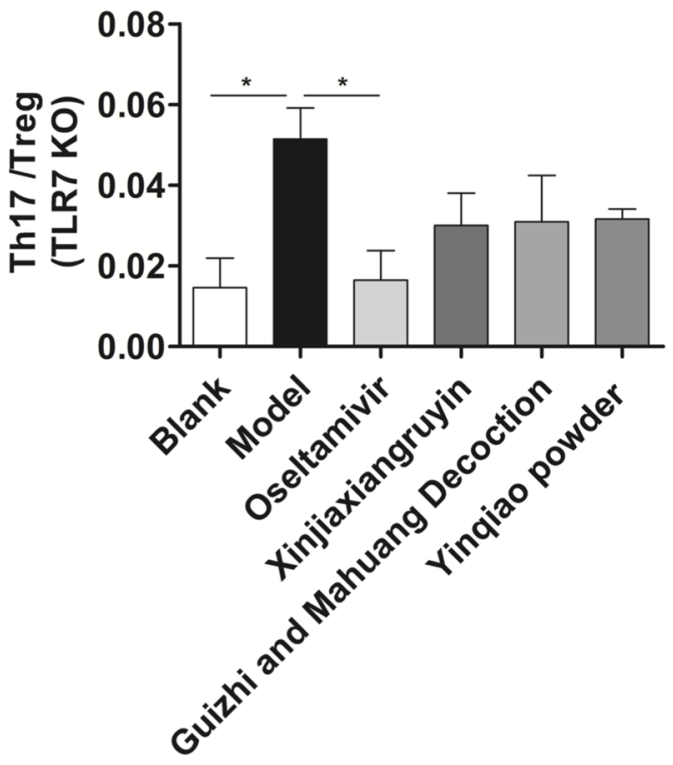

C
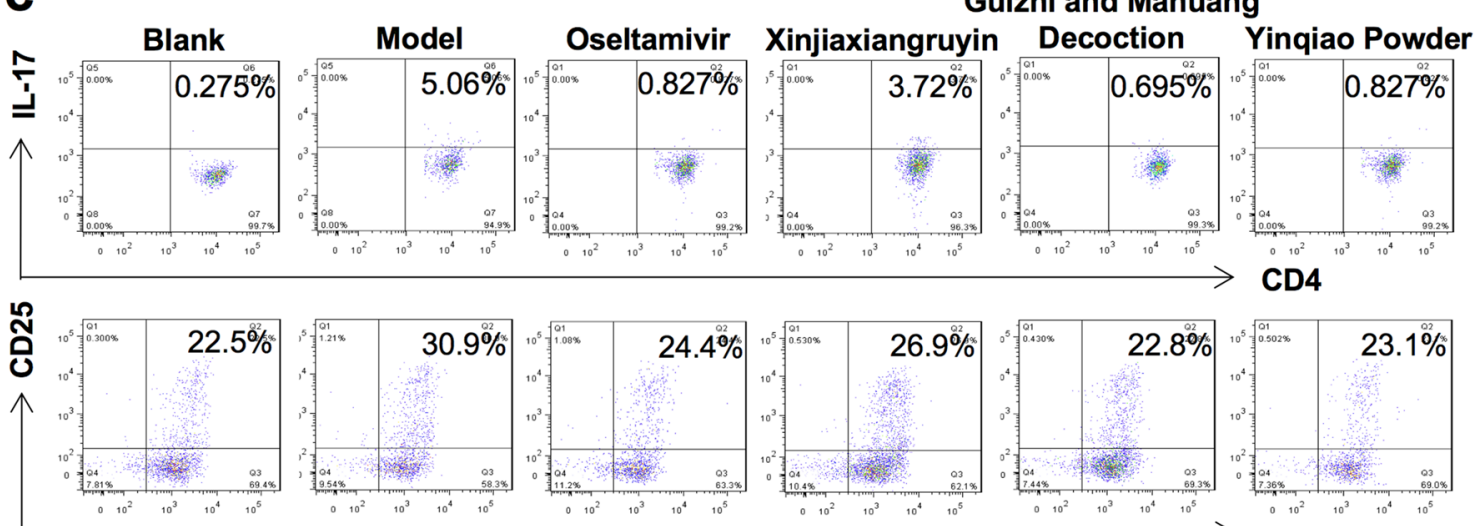

CD4

Guizhi and Mahuang

d Guizhi and Mahuang
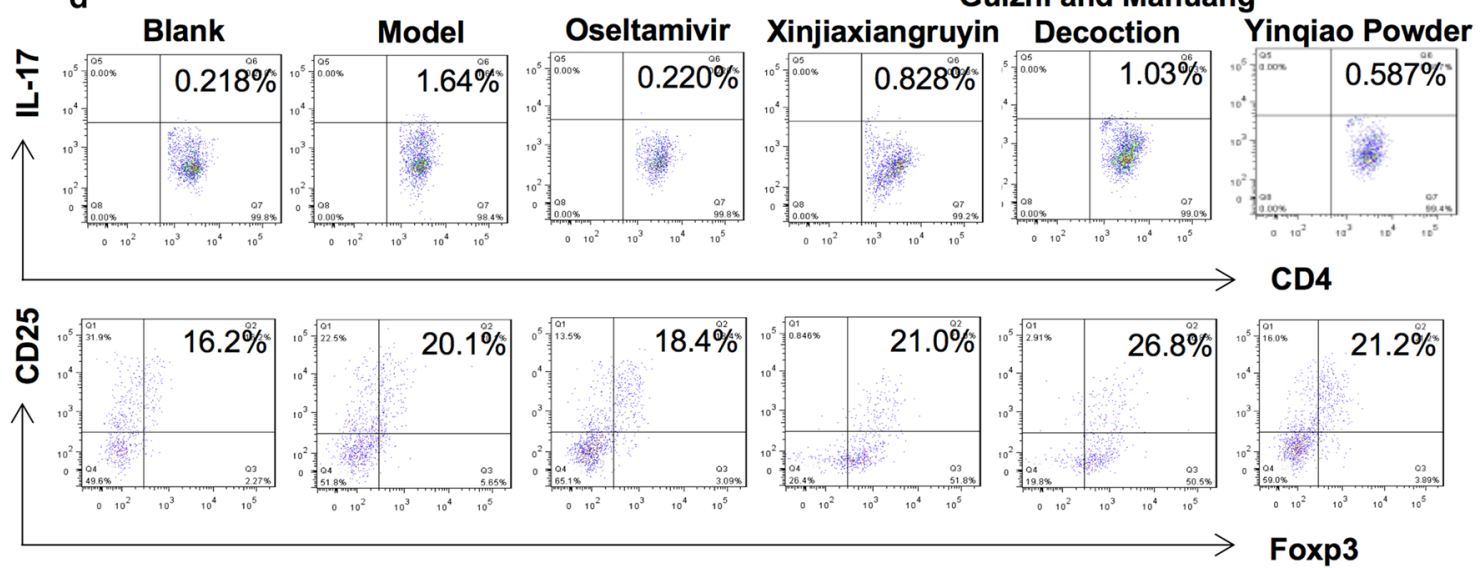

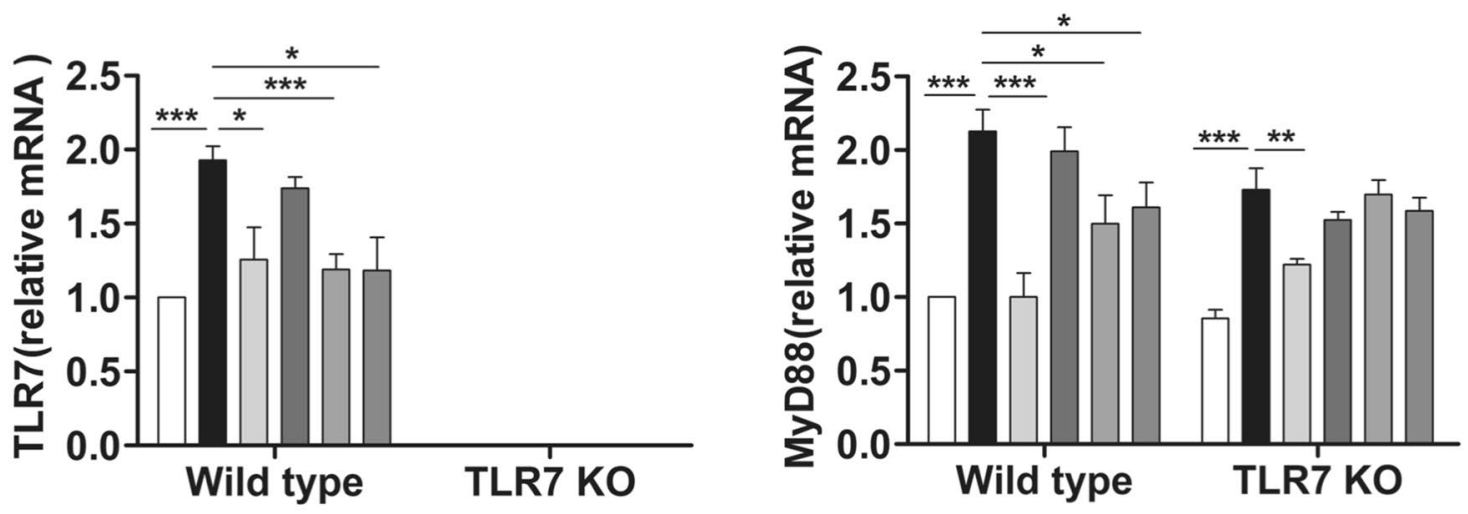

Blank

Model

Oseltamivir

Xinjiaxiangruyin

Guizhi and Mahuang Decoction

Yinqiao Powder
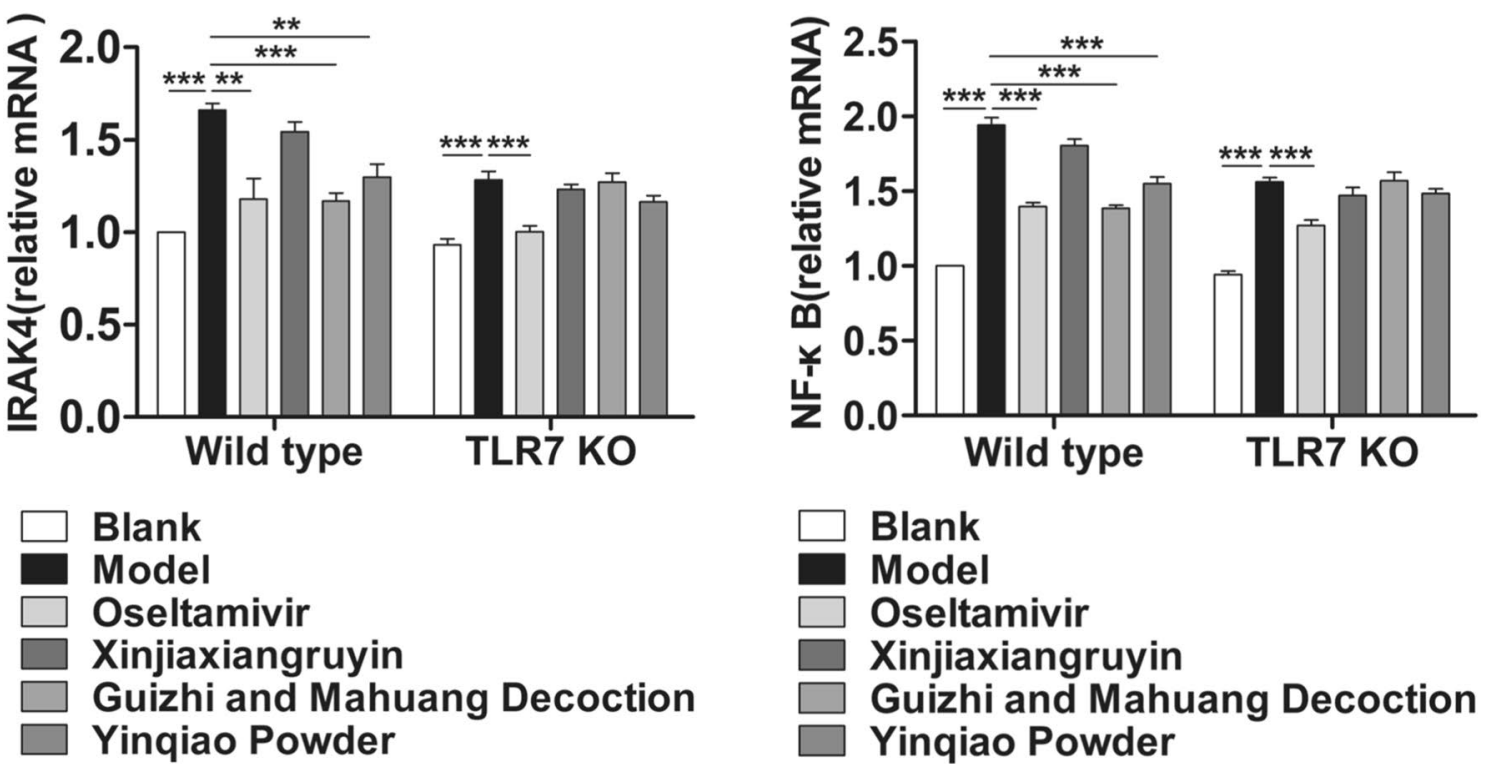

Fig. 6 The effect of different drugs on the mRNA expression of TLR7 and NF-KB signaling pathway in lung tissue of influenza virus infected mice. ${ }^{*} \mathrm{P}<0.05$, ${ }^{* *} \mathrm{P}<0.01,{ }^{* * *} \mathrm{P}<0.001$

(Xinjiaxiangruyin). In different environments, drugs may perform differently against influenza, and our experiment was carried out in the normal environment (temperature: $18-20{ }^{\circ} \mathrm{C}$, humidity $50 \%$, and light: $3000 \mathrm{Lx}$ ) for the viral infection and drug administration in mice. The experimental results indicated that under normal circumstances, Guizhi-and-Mahuang decoction and Yinqiao powder had defensive effects against influenza virus infection, while the effect of Xinjiaxiangruyin was not obvious in wild type mice. Compared to the positive control oseltamivir, Guizhi-and-Mahuang decoction showed no difference in the lung index, lung pathology change, virus load and the ratio of Th17 cells and Treg cells, demonstrating its efficacy in anti-virus and the potential as 


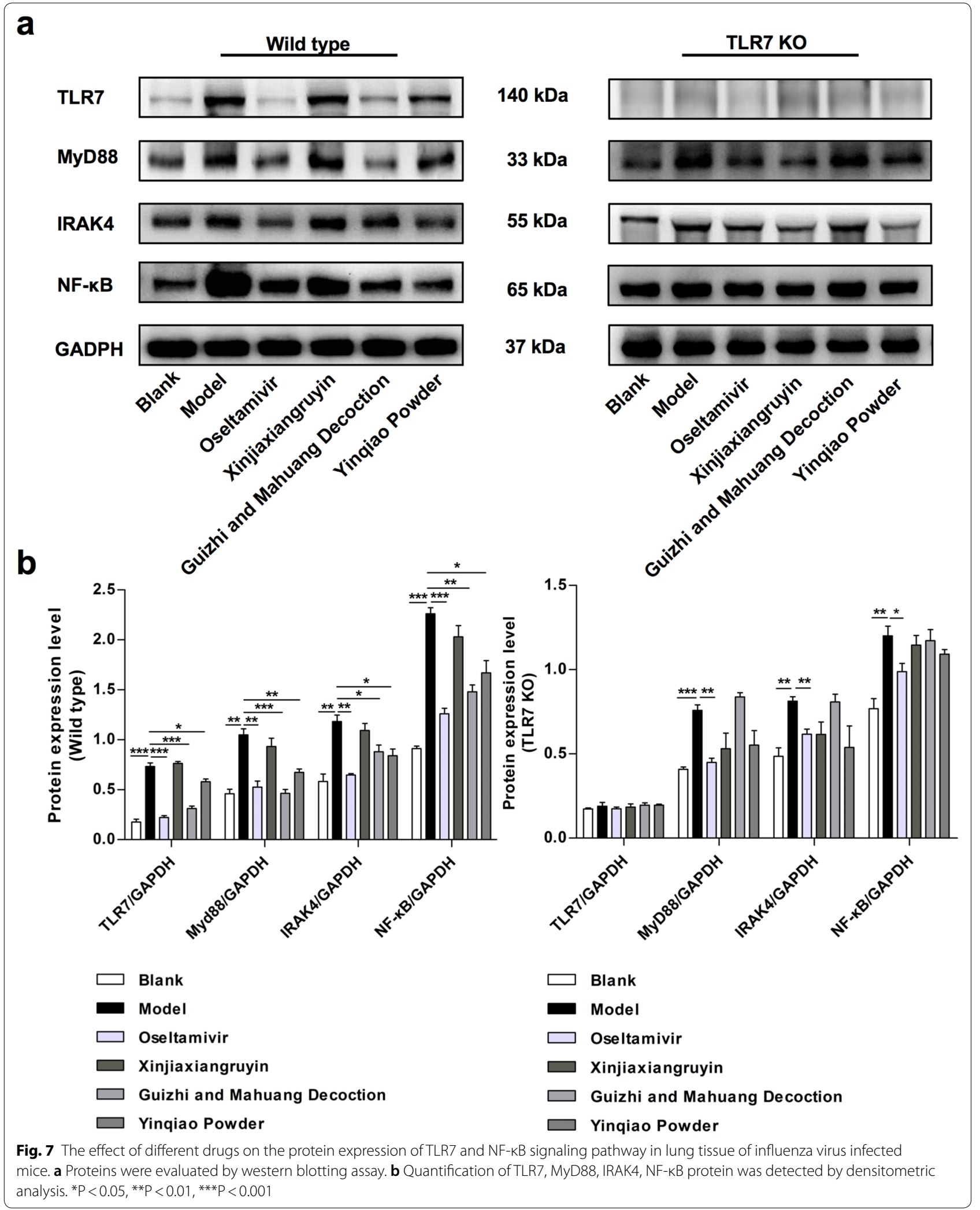


a new anti-influenza drug. Xinjiaxiangruyin may play a good role of anti-influenza in hot and humid environment, which warrants further research and exploration.

In terms of inflammatory response, we further demonstrated the role of Chinese herbal compounds in the anti-influenza process. Th17 cells secrete IL-17 as well as cytokines such as IL-21 and IL-22, and IL-17 can aggravate inflammatory reaction and participate in various autoimmune diseases [42]. Treg is a CD4+ $\mathrm{T}$ cell subset with immunosuppressive activity. Treg cells release cytokines IL-10 and TGF- beta to inhibit the function of $\mathrm{T}$ cells and antigen presenting cells, and reduce the production of inflammatory cytokines and antibody secretion. Foxp3 is an important transcription factor of Treg, and its continuous expression is the key factor in maintaining the inhibitory activity of Treg. Foxp3+ Treg cells have the function of anti-inflammatory and maintenance of autoimmune tolerance [43]. Foxp3+ Treg cells and Th17 cells inhibit each other in differentiation, development and function [44]. Therefore, Foxp3+ Treg/Th17 balance plays an important role in maintaining immune homeostasis.

Mononuclear cells were isolated from spleen of mice and flow cytometry was used to detect and analyze Th17 cells and Treg cells. The ratio of Th17 to Treg in the virus control group was much greater than that in the blank control group. In wild type mice, Oseltamivir, Guizhiand-Mahuang decoction, and Yinqiao powder could decrease the ratio of Th17/Treg, which indicated that Treg cells inhibited the release of inflammatory factors and alleviated the inflammatory response in the lungs of mice. In TLR7 KO mice, the deletion of TLR7 gene significantly decreased the antiviral effect of Guizhi-andMahuang decoction and Yinqiao powder, which indicated that these two drugs might function through TLR7. The inflammatory response in lung pathology was consistent with the ratio change of Th17/Treg cells.

At both mRNA and protein expression levels, we have demonstrated the effect of TCMs on the TLR7/NF-kB signaling pathway in the process of anti-influenza virus infection. It's found that the TLR7 was up-regulated in the macrophages upon virus infection [45]. Studies have shown that TCMs can play a role in the treatment of influenza by TLR7 mediated MyD88-dependent signaling pathway. In this study, we mainly examined the mRNA and protein expressions of components in TLR7-mediated MyD88-dependent signaling pathway. The results showed that the expression levels of TLR7, MYD88, IRAK4 and NF-kB were remarkably up-regulated upon viral infection, and Guizhi-and-Mahuang decoction and Yinqiao powder could down-regulate their expressions in wild type mice. In TLR7 KO mice, the mRNA and protein expressions of TLR7 were very low in all groups, indicating that the TLR7 gene was successfully knocked out. However, MyD88 was up-regulated upon viral infection, because all other members of TLRs family, except for TLR3, can be activated by MyD88 dependence [46]. The expression of IRAK4 was low upon viral infection, indicating that the TLR7 knockout might affect IRAK4 expression in the downstream pathway. TLR7 knockout decreased the transcription and translation levels of NF- $\kappa B$ overall, which suggested that TLR7 plays an indispensable role in the pathway. However, there was no significant change in survival rate of TLR7 KO mice, which was probably due to the compensatory role of the RLH signaling pathway. RIG-I (RIG-like receptors) is also a type of pattern recognition receptor [47] and involves in the recognition of influenza virus [48]. NF- $\mathrm{kB}$ is the common nuclear factor of TLR7 and RIG-I, so when TLR7 gene is knocked out, RIG-I may play a compensatory role, and ultimately activate NF- $\mathrm{kB}$ to maintain stable expression.

Oseltamivir is a neuraminidase inhibitor [49], which blocks the activity of neuraminidase, inhibiting the replication and toxicity of virus so as to effectively prevent and even alleviate the symptoms of influenza. It can be combined with the flu vaccine without affecting the antibody production. However, oseltamivir resistant influenza A and influenza B virus strains have continuously emerged in recent years [5], and many side effects have been reported, such as vomiting, nausea, headache, and rash [50]. TCM has a lot of advantages. It not only has the functions of inhibiting virus replication, preventing cytopathic effect, improving host immunity and blood circulation, but also greatly reduces the drug resistance due to its compatibility, which makes TCM a unique and effective option in the prevention and treatment of influenza.

\section{Conclusion}

The results of this study show that, under normal circumstances, Guizhi-and-Mahuang decoction and Yinqiao powder play a more significant role in the process of anti-influenza virus. After influenza virus infection, transcription and translation levels of components in the TLR7/NF- $\mathrm{KB}$ pathway were increased in mouse lungs, and Guizhi-and-Mahuang decoction and Yinqiao powder effectively reduced those changes to achieve viral clearance and inflammation recovery. Although different from oseltamivir in antiviral mechanisms, Guizhi-andMahuang decoction showed similar effects on therapeutic effects. 


\section{Additional file}

Additional file 1. Minimum Standards of Reporting Checklist.

\section{Authors' contributions}

JZY, TXL and CXY conceived and designed the experiments. FYJ, YYQ, QHQ and ZX performed the experiments. FYJ and YYQ analyzed the data. WS, SSS and WPC provided reagents and advice. Wrote the paper: FYJ. All authors read and approved the final manuscript.

\section{Acknowledgements}

Not applicable.

\section{Competing interests}

The authors declare that they have no competing interests.

\section{Availability of data and materials}

The data and materials generated or analyzed during this study are available from the corresponding author on reasonable request.

\section{Consent for publication}

The manuscript is approved by all authors for publication.

\section{Ethics approval and consent to participate}

The experimental protocol was established according to the ethical guidelines and was approved by the Experimental Animal Ethics Committee of Jinan University.

\section{Funding}

This work was supported by the National Natural Science Foundation of China [Grant Numbers 81473454, 81473557, 81774164] and the Natural Science Foundation of Guangdong, China [Grant Numbers 2015A030313331].

\section{Publisher's Note}

Springer Nature remains neutral with regard to jurisdictional claims in published maps and institutional affiliations.

Received: 8 May 2018 Accepted: 10 August 2018

Published online: 20 August 2018

\section{References}

1. Nogales A, Martínez-Sobrido L. Reverse genetics approaches for the development of influenza vaccines. Int J Mol Sci. 2016;18:20.

2. Ozawa M, Kawaoka Y. Crosstalk between animal and human influenza viruses. Annu Rev Anim Biosci. 2013;1:21-42.

3. Kumar A, Zarychanski R, Pinto R, Cook D, Marshall J. Critically III patients with 2009 influenza $A(H 1 N 1)$ infection in Canada. JAMA. 2009:302:1872-9.

4. Tomoko N, Kazufumi S, Torahiko T, Kazumichi K. Bacterial neuraminidase rescues influenza virus replication from inhibition by a neuraminidase inhibitor. PLoS ONE. 2012;7:e45371.

5. Poland GA, Jacobson RM, Ovsyannikova IG. Influenza virus resistance to antiviral agents: a plea for rational use. Clin Infect Dis. 2009:48:1254-6.

6. Moscon A. Neuraminidase inhibitors for influenza. New Engl J Med. 2005:353:1363.

7. Gubareva L, Okomo-Adhiambo M, Deyde V, Sheu TG, Garten R. Update: drug susceptibility of swine-origin influenza A (H1N1) viruses, april 2009. MMWR Morb Mortal Wkly Rep. 2009;58:433-5.

8. Zhang ZY, Zhang HM, Zhou Z, Wang SQ. Protective effect of Yin Qiao San on H1N1 viral infection in the mice. World J Integr Trad West Med. 2015;10:771-87.

9. Ding Y, Cao Z, Cao L, Ding G, Wang Z, Xiao W. Antiviral activity of chlorogenic acid against influenza $A(H 1 N 1 / H 3 N 2)$ virus and its inhibition of neuraminidase. Sci Rep. 2017:7:45723.
10. Qu XY, Li QJ, Zhang HM, Zhang XJ, Shi PH, Zhang XJ, Yang J, Zhou Z, Wang SQ. Protective effects of phillyrin against influenza $A$ virus in vivo. Arch Pharm Res. 2016:39:998-1005.

11. Wang Z, Xia Q, Li X, Liu W, Huang W, Mei X, Luo J, Shan M, Lin R, Zou D, Ma Z. Phytochemistry, pharmacology, quality control and future research of Forsythia suspensa (Thunb.) Vahl: a review. J Ethnopharmacol. 2018:210:318-39.

12. Kobayashi M, Davis SM, Utsunomiya T, Pollard RB, Suzuki F. Antivrial effect of Gingyo-san, a traditional Chinese medicine herbal medicine, on influenza A2 virus in mice. Am J Med. 1999;27:53-62.

13. Hayashi K, Narutaki K, Nagaoka Y, Hayashi T, Uesato S. Therapeutic effect of arctiin and arctigenin in immunocompetent and immunocompromised mice infected with influenza A virus. Biol Pharm Bull. 2010:33:1199-205.

14. Deng L, Nie J, Pang P, Chen XY. Comparative study on the effects of Xinjiaxiangruyin in influenza viral pneumonia mice in a damp and hot environment. J New Chin Med. 2016;48:235-8.

15. Ding CX, Ju JL. Research advance of the chemical componentand pharmacological action of elsholtzia. Shanghai J Trad Chin Med. 2005;39:64.

16. Bao Z, Yang X, Ding Z, Cao Q, Zou Y. Simultaneous determination of magnolol and honokiol by UV spectrophotometry and study on free radical scavenger activity. Nat Prod Res Devel. 2004;16:435-8.

17. Schuhly W, Hufner A, Pferschy-Wenzig EM, Prettner E, Adams M, Bodensieck A, Kunert O, Oluwemimo A, Haslinger E, Bauer R. Design and synthesis of ten biphenyl-neolignan derivatives and their in vitro inhibitory potency against cyclooxygenase-1/2 activity and 5-lipoxygenasemediated LTB4-formation. Bioorg Med Chem. 2009;17:4459-65.

18. Shen P, Zhang Z, He Y, Gu C, Zhu K, Li S, Li Y, Lu X, Liu J, Zhang N, Cao Y. Magnolol treatment attenuates dextran sulphate sodium-induced murine experimental colitis by regulating inflammation and mucosal damage. Life Sci. 2018:196:69-76.

19. Li M, Zhang F, Wang X, Wu X, Zhang B, Zhang N, Wu W, Wang Z, Weng H, Liu S, Gao G, Mu J, Shu Y, Bao R, Cao Y, Lu J, Gu J, Zhu J, Liu Y. Magnolol inhibits growth of gallbladder cancer cells through the p53 pathway. Cancer Sci. 2015;106:1341.

20. Fang CY, Chen SJ, Wu HN, Ping YH, Lin CY, Shiuan D, Chen CL, Lee YR, Huang KJ. Honokiol, a lignan biphenol derived from the magnolia tree, inhibits dengue virus type 2 infection. Viruses. 2015;7:4894-910.

21. Lan KH, Wang YW, Lee WP, Lan KL, Tseng SH, Hung LR, Yen SH, Lin HC, Lee SD. Multiple effects of Honokiol on the life cycle of hepatitis C virus. Liver Int. 2012;32:989-97.

22. Ma L, Li JB, Sheng D, Liu Y. Effect of three therapies on interleukin 2 and $t$ lymphocyte subgroups in mice infected with influenza a virus of type 1 or type 3. Chin J Exp Trad Med Formulae. 2010;16:108-11.

23. Jia CH, Pang ZR, Yang HM, Wei XF, Liu BS, Zhao TH, Yang HS. Pharmacodynamic study on the antipyretic and analgesic effect of GUI Ma He Fang. Chin J Basic Med Trad Chin Med. 2004;10:32-4.

24. Liu XG, Jia CH, Guo YC, Li JH, Li XJ, Pang ZR. Effects of GUI Ma He Fang on asthma latent period and pathological changes of lung tissue in asthmatic guinea pigs. J Chengde Med Coll. 2006;23:3-6.

25. Dai GD, Zheng P, Li HQ. Action of pseudo-ephedrine and ephedrine on the rings of isolated rabbit's and rat's aorta. J Ningxia Med Coll. 2001:23:318-9.

26. Hayashi K, Imanishi N, Kashiwayama Y, Kawano A, Terasawa K, Shimada Y, Ochiai $\mathrm{H}$. Inhibitory effect of cinnamaldehyde, derived from Cinnamomi cortex, on the growth of influenza A/PR/8 virus in vitro and in vivo. Antiviral Res. 2007;74:1-8.

27. Ding Y, Qiu L, Zhao G, Xu J, Wang S. Influence of cinnamaldehyde on viral myocarditis in mice. Am J Med Sci. 2010;340:114-20.

28. Lin YC, Huang DY, Chu CL, Lin WW. The tyrosine kinase Syk differentially regulates toll-like receptor signaling downstream of the adaptor molecules TRAF6 and TRAF3. Sci Signal. 2013;6:71.

29. Lund JM, Alexopoulou L, Sato A, Karow M, Adams NC, Gale NW, Iwasaki A, Flavell RA. Recognition of single-stranded RNA viruses by Toll-like receptor 7. P Natl Acad Sci. 2004;101:5598-603.

30. Blasius AL, Beutler B. Intracellular toll-like receptors. Immunity. 2010;32:305-15.

31. Diebold SS, Kaisho T, Hemmi H, Akira S. Reis CeS. innate antiviral responses by means of TLR7-mediated recognition of single-stranded RNA. Science. 2004;303:1529. 
32. Iwasaki A, Medzhitov R. Toll-like receptor control of the adaptive immune responses. Nat Immunol. 2004;5:987.

33. Takeda K, Akira S. TLR signaling pathways. Semin Immunol. 2004;16:3-9.

34. Du X, Poltorak A, Wei Y, Beutler B. Three novel mammalian Toll-like receptors: gene structure, expression, and evolution. Eur Cytokine Netw. 2000;11:362-71

35. Lee J, Chuang TH, Redecke V, She L, Pitha PM, Carson DA, Raz E, Cottam HB. Molecular basis for the immunostimulatory activity of guanine nucleoside analogs: activation of Toll-like receptor 7. Proc Natl Acad Sci. 2003; 100:6646-51.

36. Heil F, Ahmad-Nejad P, Hemmi H, Bauer S. The Toll-like receptor 7 (TLR7)specific stimulus loxoribine uncovers a strong relationship within the TLR7, 8 and 9 subfamily. Eur J Immunol. 2010:33:2987-97.

37. Livak KJ, Schmittgen TD. Analysis of relative gene expression data using real-time quantitative $P C R$ and the $2^{-\triangle \triangle C a}$ method. Methods. 2001;25:402-8.

38. Dovedi SJ, Melis MH, Wilkinson RW, Adlard AL, Stratford IJ, Honeychurch J, Illidge TM. Systemic delivery of a TLR7 agonist in combination with radiation primes durable antitumor immune responses in mouse models of lymphoma. Blood. 2013;121:251-9.

39. Walter A, Schafer M, Cecconi V, Matter C, Urosevic-Maiwald M, Belloni B, Schonewolf N, Dummer R, Bloch W, Werner S, Beer HD, Knuth A, van den Broek M. Aldara activates TLR7-independent immune defence. Nat Commun. 2013;4:1560

40. Greiff $L$, Cervin A, Ahlstrom-Emanuelsson C, Almqvist G, Andersson M, Dolata J, Eriksson L, Hogertatt E, Kallen A, Norle P, Sjolin IL, Widegren H. Repeated intranasal TLR7 stimulation reduces allergen responsiveness in allergic rhinitis. Respir Res. 2012;13:53.
41. Hemmi H, Kaisho T, Takeuchi O, Akira S. Small anti-viral compounds activate immune cells via the TLR7 MyD88-dependent signaling pathway. Nat Immunol. 2002:3:196-200.

42. Yang JN, Liu XG, Li T, Chen H, Zhang YY. Function of Th17/Treg balance in rheumatoid arthritis. Chin Pharmacol Bull. 2013;29:1045-8.

43. Ray A, Khare A, Krishnamoorthy N, Qi Z, Ray P. Regulatory T cells in many flavors control asthma. Mucosal Immunol. 2010:3:216-29.

44. Ivanov II, Zhou L, Littman DR. Transcriptional regulation of Th17 cell differentiation. Semin Immunol. 2007:19:409-17.

45. Chen C, Jiang ZY, Yu B, Wu XL, Dai CQ, Zhao CL, Ju DH, Chen XY. Study on the anti-H1N1 virus effects of quercetin and oseltamivir and their mechanism related to TLR7 pathway. J Asian Nat Prod Res. 2012;14:877-85.

46. Kawai T, Akira S. Toll-like receptors and their crosstalk with other innate receptors in infection and immunity. Immunity. 2011;34:637-50.

47. Kutikhin AG, Yuzhalin AE. C-type lectin receptors and RIG--like receptors: new points on the oncogenomics map. Cancer Manag Res. 2012:4:39-53.

48. Yoneyama M, Kikuchi M, Natsukawa T, Shinobu N, Imaizumi T, Miyagishi M, Taira K, Akira S, Fujita T. The RNA helicase RIG-I has an essential function in double-stranded RNA-induced innate antiviral responses. Nat Immunol. 2004:5:730-7.

49. Stephenson I, Democratis J, Lackenby A, Mcnally T, Smith J, Pareek M, Ellis J, Bermingham A, Nicholson K, Zambon M. Neuraminidase inhibitor resistance after oseltamivir treatment of acute influenza $A$ and $B$ in children. Clin Infect Dis. 2009;48:389-96.

50. Strong M, Burrows J, Stedman E, Redgrave P. Adverse drug effects following oseltamivir mass treatment and prophylaxis in a school outbreak of 2009 pandemic influenza A(H1N1) in June 2009, Sheffield, United Kingdom. Euro Surveill. 2010;15:19565.
Ready to submit your research? Choose BMC and benefit from:

- fast, convenient online submission

- thorough peer review by experienced researchers in your field

- rapid publication on acceptance

- support for research data, including large and complex data types

- gold Open Access which fosters wider collaboration and increased citations

- maximum visibility for your research: over 100M website views per year

At BMC, research is always in progress.

Learn more biomedcentral.com/submissions 